\title{
Design and evalution of a solar PV system
}

\author{
Emad Jaleel Mahdi, Ali Huseen Obaid, Imad Jawad Khadim, Amar Abaas Fadeel, \\ Ammar Nouri Jaffer, Emad Mutaab Muhseen, Adil Abd Al-Shahup Jasim,
}

Ali Sabeeh Al-Gani, F.I. Mustuf

Directory of Renewable energy, Solar Energy Research Center, Ministry of Science and

Technology

E-mail: imad_jk@yahoo.com

\begin{abstract}
Key words

PV connected systems are worldwide installed because it allows consumer to reduce energy consumption from the electricity grid. This paper presents the results obtained from monitoring a $1.1 \mathrm{kWp}$. The system was monitored for nine months and all the electricity generated was fed to the fifth floor for physics and renewable energy building $220 \mathrm{~V}, 50 \mathrm{~Hz}$. Monthly, and daily performance parameters of the PV system are evaluated which include: average generated of system Ah per day, average system efficiency, solar irradiation around these months. The average generated $\mathrm{kWh}$ per day was 8 $\mathrm{kWh} /$ day, the average solar irradiation per day was $5.6 \mathrm{kWh} / \mathrm{m}^{2} /$ day, the average inverter efficiency was $95 \%$, the average modules efficiency was $12 \%$.

pv system projects, photovoltaic systems, solar panel.

\section{Article info}

Received: Dec. 2012

Accepted: May. 2013

Published: Sep. 2013

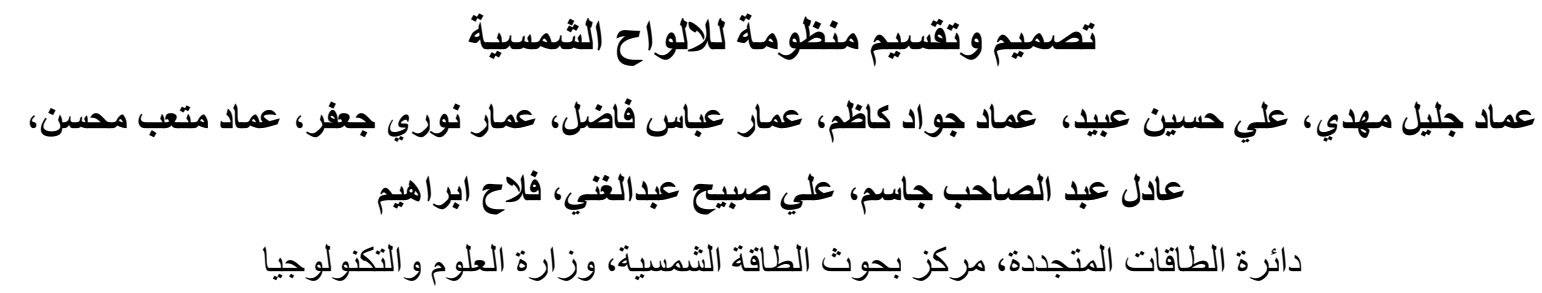

الخلاصة

تم تنصيب منظومات الخلايا الثمسية بشكل و اسع وذلك لمساهمة المستخدم بتقليل القدرة المستهلكة من الثبكة الوطنيـة. وهذه وهنه

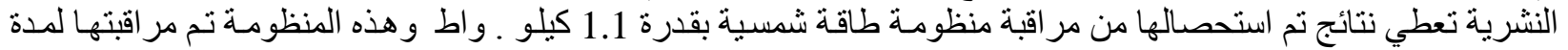

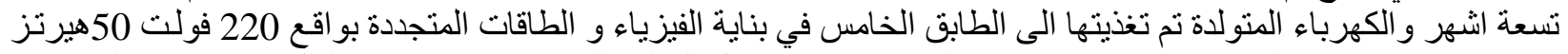

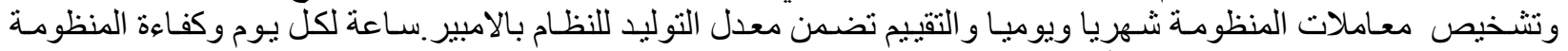

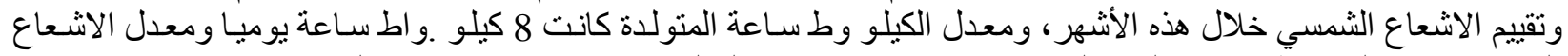

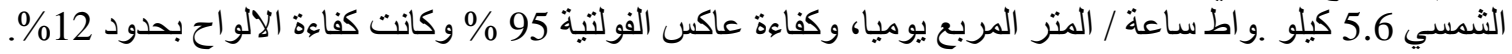

\section{Introduction}

Photovoltaic (PV) technology converts one form of energy (sunlight) into another form of energy (electricity) using no moving parts, consuming no conventional fossil fuels, creating no pollution, and lasting for decades with very little maintenance [1]. In general, PV materials are categorized as either crystalline or thin film, and they are judged on two basic factors: efficiency and economics. It is also worth noting that the conversion efficiency of thin-film panels tends to drop off rather rapidly in the first 
few years of operation. Which PV technology is more appropriate for a given application will need to be determined on a case-by-case basis. Polycrystalline silicon panels have efficiencies of $12 \%$ to $14 \%$ and can often be purchased at a lower cost per watt than mono crystalline silicon panels.

A battery stores electrical energy in the form of chemical energy. For a PV-battery system to function effectively, the electrochemical processes must work in both directions. To this end, batteries perform three main functions in a stand-alone PV system:

1. Autonomy-by meeting the load requirements at all times, including at night, during overcast periods, or during the winter when PV input is low or absent.

2. Surge-current capability -by supplying, when necessary, currents higher than the PV array can deliver, especially to start motors or other inductive equipment.

3. Voltage control-thereby preventing large voltage fluctuations that may damage the load.

Any battery suitable for PV applications will be a deep-cycle type of battery as opposed to a starting SLI type (starting, lighting, ignition to power the starter motor, the lights, and the ignition system of a vehicle's engine). Although these two fundamental classes of batteries may appear similar on the outside, the internal structure is quite different. SLI batteries are intended to deliver a high-amperage output for a short period of time, but repeated deep discharges cause rapid deterioration of battery performance. These batteries are typically rated in cranking amps, or cold cranking amps (CCA). Deep-cycle batteries are designed to deliver a typically lower current for the size of the battery, but they are capable of withstanding numerous deep discharges without damage [2].

The amount of energy a deep-cycle battery can store is referred to as its capacity. The unit that describes capacity is the amp hour (Ah). Deep-cycle batteries vary widely in type, price, and quality. Lowcost trolling batteries represent the low end of the scale and are generally not suitable for use in remote power applications. The depth of discharge $(D O D)$ also has a direct bearing on how long a battery will last. A battery discharged to $50 \%$ on each cycle will last about twice as long as one discharged to $80 \%$ per cycle. This is a major issue for polar researchers wishing to run PVpowered experiments over the length of a polar winter when little or no solar insolation is available to recharge the battery bank [3].

Greater functionality will be required for more complex systems and those that are deployed year-round. Charge controller functions include the following:

The simplest charge controllers really only perform the overcharge protection function. It is essentially an on/off switch for the PV panels. The next level of sophistication allows for changing the charge parameters. For instance, the voltage level can be set to accommodate the differences between flooded-cell, gel-cell, and AGM-type batteries (An absorbed glass mat battery has the electrolyte absorbed in a fiber-glass mat separator and do not require regular addition of water to the cells).

Alternating current is easier to transport over long distances and has become the conventional modern electrical standard. There are two fundamental categories of inverters: synchronous and static or standalone. Synchronous inverters are capable of being tied into the electrical grid, or utility power.

A second inverter classification refers to the type of AC waveform they produce. Inverters are available in square wave, modified square wave, and sine wave outputs. Square wave inverters are inexpensive, but they typically provide poor 
output voltage control, limited surge capacity, and significant amounts of harmonic distortion. In general, this type of inverter is inappropriate for remote scientific research applications $[4,5]$. When selecting an inverter, many additional criteria must be considered: DC voltage input must match the battery voltage of the system. AC power output must be adequate to satisfy the maximum-potential combined $\mathrm{AC}$ load, or all of the AC-powered equipment that might be on at one time. Voltage and frequency regulation should be very tight in a highquality unit. Voltage and frequency should match the system requirements $(60 \mathrm{~Hz} / 120$ volts for U.S. equipment and $50 \mathrm{~Hz} / 240$ volts for European equipment). Efficiency should be high across a broad range of output levels. Choose an inverter rated for high efficiency over a wide range of load conditions. Construction should be consistent with the application requirements[6].

\section{Experimental materials}

Load in solar research center

Finding out and understanding the total energy consumption of sixth floor in my directory is the first step through designing an Energy Program for fourth floor in renewable energy directory. In this part we observed the data of energy consumption figures and facts of fourth floor in renewable energy directory. We collected the peak and off peak data. We analyzed the daily load about $8 \mathrm{kwh}$ shown in Table 1 .

\section{Selecting the PV module}

we selected mono crystalline silicon module. Our module selection depends on cost and efficiency. The capital investment of solar PV panel is very high. Approximately, 60\% of the total system installation cost is the price of module cost. We have selected a module of (sharp - NE80E2EA). The model has maximum output power is 80 watt if irradiance is 1000 watts per meter square. 25 years power output warranty is $80 \%$. The panel efficiency is $13 \%$. Short circuit current of the panel is $5.15 \mathrm{~A}$ at standard test condition.

\section{Inverter selection}

We selected a PV inverter. The model is SU Kiven type (India) 3.5 KVA. The input voltage range: 48- $60 \mathrm{~V}$, Output power: $3.5 \mathrm{~kW}$, Connection: $50 \mathrm{~Hz}$ grid frequency and 2 phase 2 wire connection, The efficiency of this inverter: $98 \%$..AC voltage: 230 Volt as shown in Fig.1.

\section{Solar charge controller sizing}

The solar charge controller is typically rated against Amperage and Voltage capacities. Select the solar charge controller to match the voltage of PV array and batteries and then identify which type of solar charge controller is right for your application. We sure that solar charge controller has enough capacity to handle the current from PV array, PWM (Pulse width modulated) Solar charge controller : power master type PM -SCC-60AP-1248R (3 stage pulse width modulated charge control) (Taiwan) I/P: 12V DC- 48 VDC (60A), PUSH : Display select, HOLD: Rest . AmpHour shown in Fig.1.

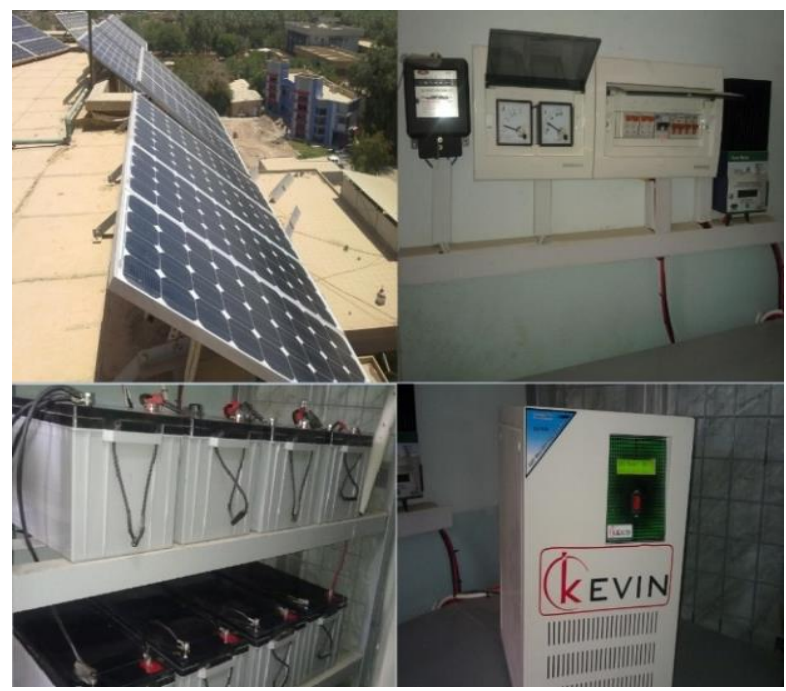

Fig.1: PV inverter model SU Kiven type (India) 


\section{Combiner box selection}

The model of selected combiner box is, the no. of input circuit: 8 , maximum input fuse rating: $5 \mathrm{~A}, 50 \mathrm{~V} \mathrm{DC}$, maximum output current: 60 A DC. We will need combiner box is equal to the number of inverter. so, we will need 2 combiner boxes.

\section{Wiring}

Rated short circuit current is $4.8 \mathrm{~A}$ from the PV module. If there is an effect of higher insolation and lower temperature access current can flow. To prevent these to happen the safety factor is considered. Average insolation at Baghdad city is $700 \mathrm{~W} / \mathrm{m}^{2}$. Therefore maximum short circuit current will be $=5.51 \mathrm{~A}$, For 7 parallel string $=7 *$ 5.51 A $=38.57 \mathrm{~A}$, considering 35\% safety factor Maximum current rating is $52.07 \mathrm{~A}$. So, we have chosen $37 \mathrm{~A}$ rating wiring.

\section{Energy supplied by the proposed PV solar system}

The designed solar system of fifth floor roof in renewable energy directory. This configuration that there is two combiner connected with $28 \mathrm{PV}$ module. $4 \mathrm{PV}$ modules in series in a string and there are 7 strings in parallel. The solar irradiance in Baghdad is about 700 watt/day. The energy supplied by the solar PV system in a year can be found by the following formula.

Total energy supply = Maximum Power at defined irradiance of a solar panel * Average bright sunshine hour $* 365$ days $*$ total no. of solar panels

$=80 * 5.7 * 365 * 28=4660320 \mathrm{Wh} /$ year

considering $80 \%$ of panel's output efficiency the total energy supply $=3728256 \mathrm{Wh} /$ year, the daily output energy is $10214.4 \mathrm{Wh}$ /day

\section{DATA Analysis and Results}

Using hourly data for the typical, hourly solar radiation, and hourly for the period
18/8 August 2011 to 31 May, for 9 month from Handel solar power meter type (TES 1333R Data logging solar power meter) have detector direct radiation are shown graphically in Fig. 2 we show decreased the solar radiation with time because the amount of radiation that reaches the ground is very variable, and it depends on various factors, for example weather conditions, the time of the year, the time of the day and location. Variations in solar radiation and ambient temperature from month-to-month influence the performance parameters. Therefore, it is important to identify which performance parameters are suitable for which system evaluations based on their weather-dependence. The charge controller, also known as a regulator, is used in PV power supplies with battery bank. The charge controller monitors (PWM type) the charge status of the battery controls the charging process and the connection/disconnection of the loads, when the battery is fully charged and the PV module is still producing energy, the charge controller will disconnect the battery automatically. This can be done by opening the circuit between the battery and the module; in case of a controller with Pulse Width Modulation (PWM) (as is the case with the Steca regulator) the charge current is modulated by means of a PWM technique. The charge current is composed of a series of pulses of which the pulse duration can be varied. As shown in Fig.3 when the generated energy by solar panels status is low or high with solar radiation state depending on weather station like clouds or dust storms appear, when irradiance was below, we can read the generated energy value from low value. 
Table 1: The total power.

\begin{tabular}{|c|c|c|c|c|c|}
\hline Name the load & Number & $\begin{array}{c}\text { power of } \\
\text { load (watt) }\end{array}$ & $\begin{array}{c}\text { Total of } \\
\text { power (watt) }\end{array}$ & $\begin{array}{c}\text { Operati } \\
\text { on hours }\end{array}$ & $\begin{array}{c}\text { Total } \\
\text { energy(watt.hours } \\
\text { ) }\end{array}$ \\
\hline Light & $26 \mathrm{lamp}$ & 20 & 520 & 6 & 3120 \\
\hline Fans & 1 & 65 & 65 & 6 & 390 \\
\hline Computer lap top & 1 & 65 & 65 & 6 & 390 \\
\hline TV + satellite & 1 & 450 & 450 & 3 & 1050 \\
\hline laser printer & 1 & 750 & 750 & 1 & 750 \\
\hline Cooler & 1 & 550 & 550 & 2 & 1100 \\
\hline Total & & $1900 \mathrm{watt}$ & $2400 \mathrm{watt}$ & & 6800 watt .hours \\
\hline
\end{tabular}

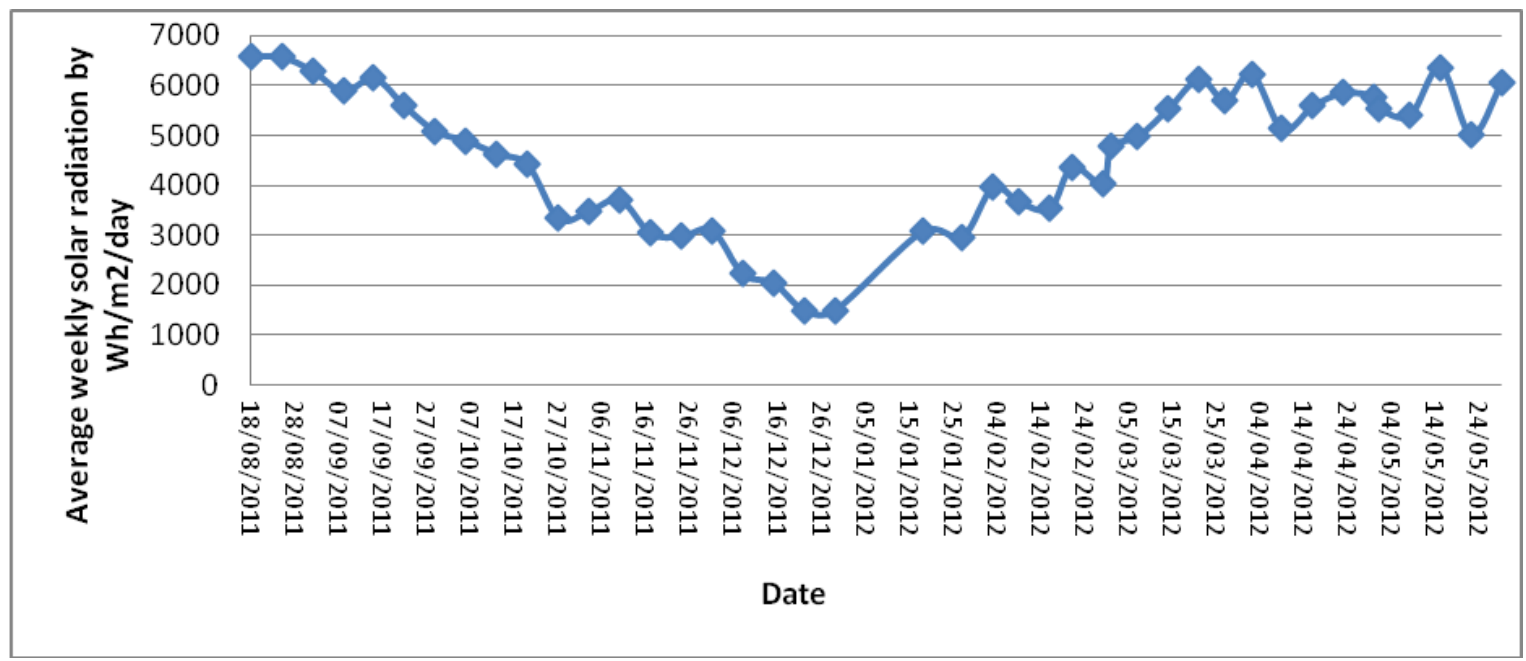

Fig.2: The average weekly solar radiation by Wh/m2/day with time.

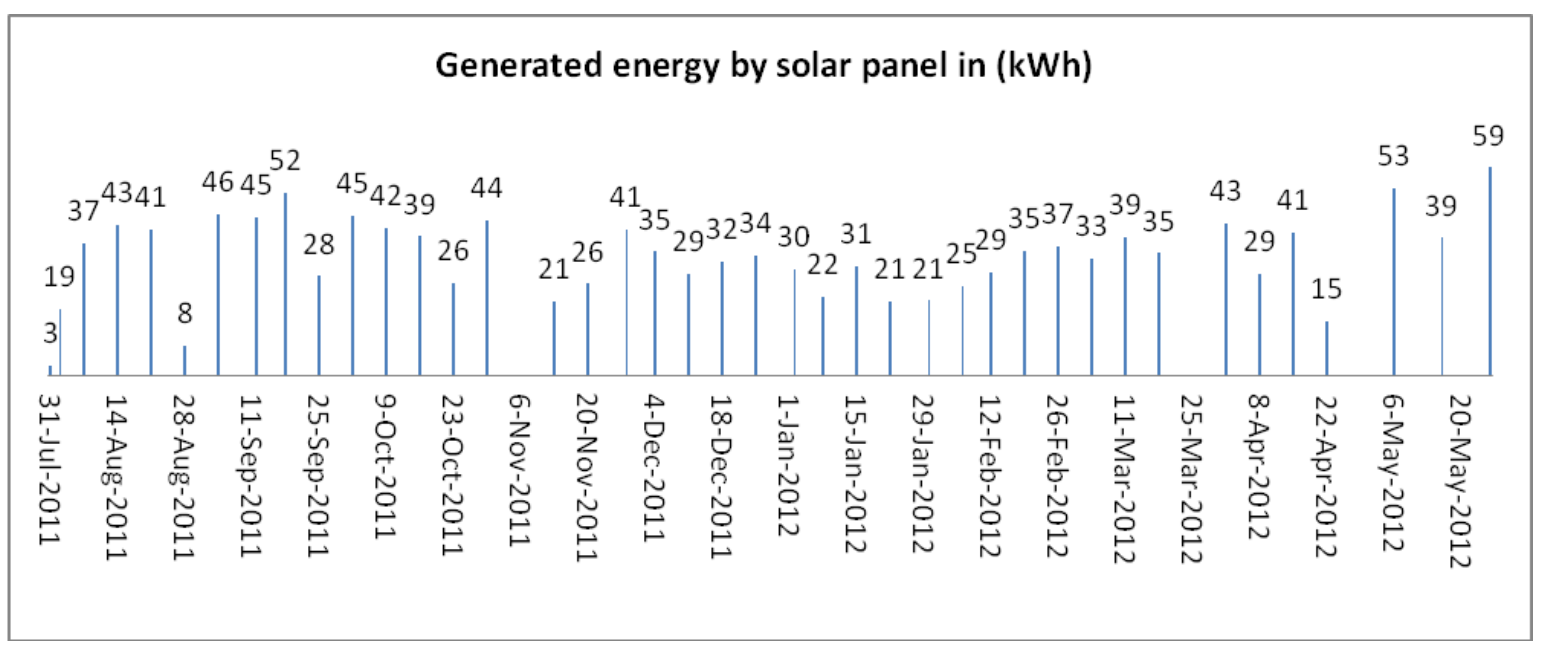

Fig. 3: The generated energy by solar panels in (KWh) with time.

Batteries are often used in autonomous PV systems for the purpose of storing electrical energy produced by the PV array during the day, and supplying it to electrical loads as needed during the day, the batteries are charged by the PV modules in periods with 
high irradiation and have different characteristics compared with being used in 5 days per week and we show in Fig. 4 the batteries voltage with time, the batteries are charged and discharged daily, most of the time the batteries are not fully charged due to short charging time available used the electric power from to load, exposed to low state of charge conditions for a long time, especially in the winter period, or exposed to a high ambient temperature in summer, The capacity of a battery is the quantity of charge (expressed in Ah) which can be withdrawn from a fully charged battery. The capacity depends both on the size of the discharge current and on the temperature of the battery. The State of Charge (SOC) of a battery indicates the relative quantity of charge available in a battery specialist in the first day from the week. The SOC is $100 \%$ and the battery is fully charged; the SOC is $50 \%$ in the end of week and the battery is fully discharged from the load the discharging voltage decreased slightly with time while the of battery be drop in the 5th day from the week.

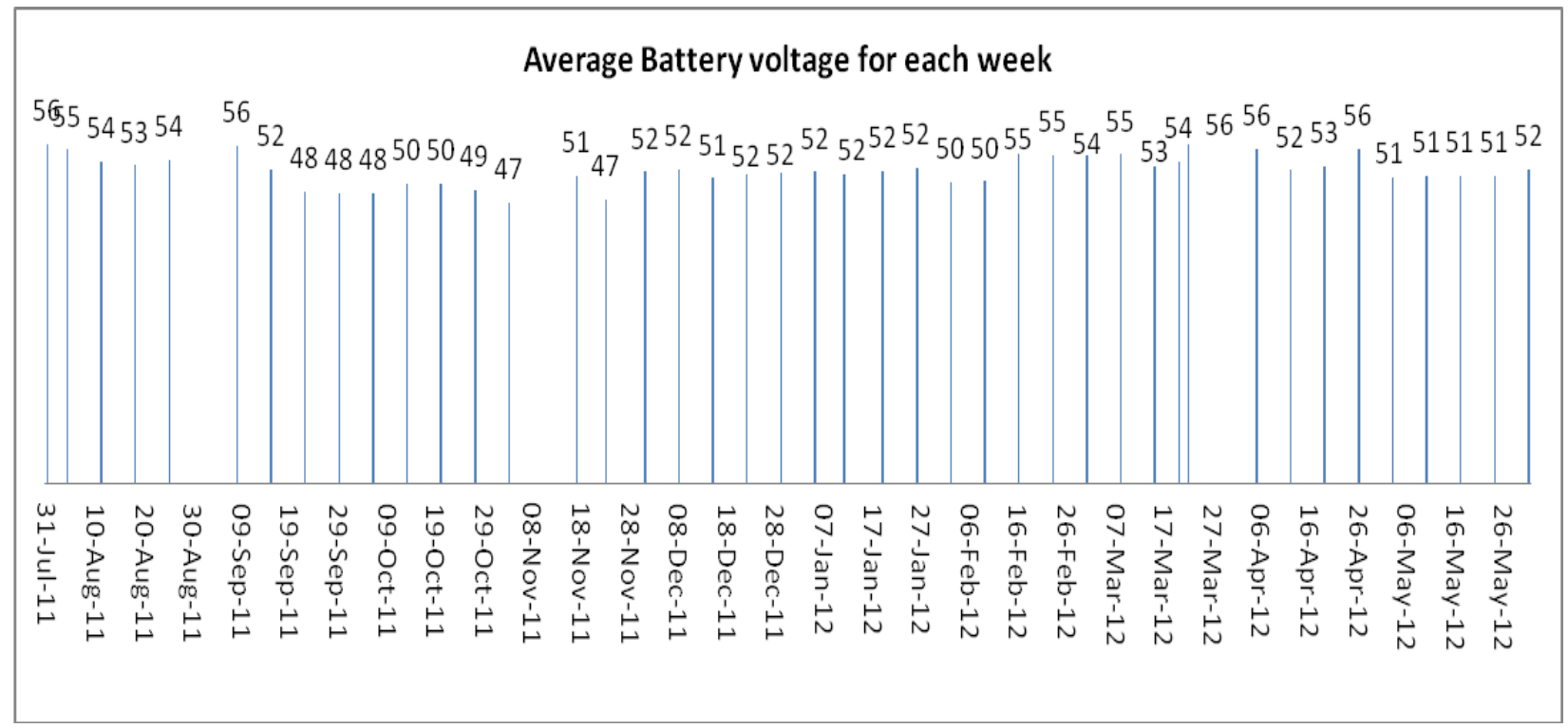

Fig. 4: The average Battery voltage for each week with time.

The first, most important, and perhaps most difficult challenge during array performance characterization is to determine an accurate value for the array short-circuit current (Isco) at a desired reference condition. After Isco has been determined, the remainder of the array performance analysis becomes self consistent and straight forward. The measurement of energy output and ambient conditions we can find out that with a higher irradiance and lower cell temperature, the PV module can generate more energy In this project can be drawn as load energy in (KWh/week) with time shown in Fig.5 The total amount of energy, the actual array operating condition during testing is determined by four factors: solar irradiance composed of a beam and a diffuse component, solar spectrum, solar angle-ofincidence, and array temperature. The typical effects of solar spectrum and angleof-incidence on module performance were previously the chart in Fig. 5 illustrates the calculated dc-energy available from the array on a monthly basis. In this case, hourly-average values for solar irradiance and for module temperature were used in the array performance model. The chart also 
shows the calculated ac-energy available from the system where the performance characteristics (efficiency versus power level) for the inverter were included in the analysis the energy loss associated with inverter efficiency is evident as the difference between the predicted array dcenergy and the measured ac-energy. The inverter self limits input power when the power available from the array exceeds the inverter's rating.

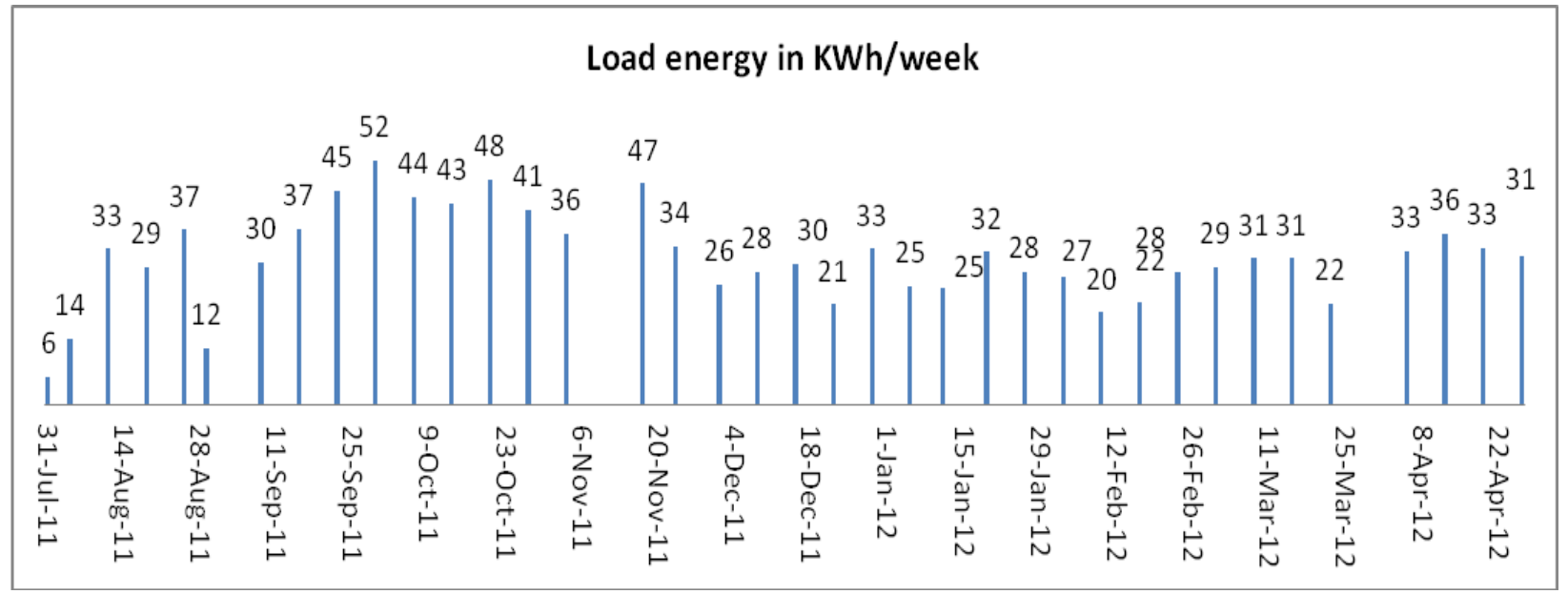

Fig.5: The load energy in KWh/week with time.

The farmstead annual electric energy use calculated by PV systems, from the hourly load averages, was $7 \mathrm{kWh}$ per day. This energy used was independent of the PV peak rated power and was covered by part of the energy produced by the PV array, the PV load coverage (amount of on-site demand supplied by the PV array) reached of about $1792 \mathrm{kWh}$ at a peak rated power of about $2240 \mathrm{Wp}$.

\section{Conclusions}

This paper addresses the improvement in the performance of the photovoltaic system by based on the energy flows obtained from the nine months -long operation system, the PV energy that met load did show a linear relationship to the PV array size. On the other hand, the cost per unit of energy for any size of PV system was greater than the cost per unit of energy for a pv system supplying the same load alone. In fact, if the PV array was sized at $12 \mathrm{kWph}$ to supply the average daily load with the average daily irradiation, the cost per unit of energy was many times the retail utility energy price. The reason for this high cost was mainly the capital cost involved in the PV modules, which dominates the economics of the system. We are facing fuel shortage for electricity generation and in the near future the whole world going to face the same scarcity because of world's limited fuel stock. So worldwide renewable energy demand and research are rising and our government also taking steps for green energy.

\section{References}

[1] A. Hunter, F. Kenneth and R. Henderson "Measured performance of a 35 kilowatt roof top photovoltaic system" International Solar Energy Conference Hawaii, USA, ISEC2003-44230, (2003).

[2] H. Xuehao, Z. Xiaoxin and B. Xiaoming, Science and Technology Review, 11 (2004) 4-8. [3] M. Šuri, T.A. Huld, E.D. Dunlop, H.A. Ossenbrink. Sol Energy, 81 (2007) 1295-305. 
[4] J.K. Kaldellis, Spyropoulos, G.C., Kavadias, K.A. Koronaki, Renewable Energy 34,4 (2009) 1106-1113.

[5] P. Denholm, E. Drury, R.Margolis, Mehos, "Solar energy: the largest energy resource. In: Sioshansi", F.P. (Ed.), Generating Electricity in a Carbon- constrained World. Academic Press, California, (2010) 271-302.

[6] W.Tian, Y.Wang, J. Ren, Zhu. Energy Conversion and Management, 48 ,1 (2007) $1-8$. 